\title{
Extrathoracic lymph node aspiration in bronchial carcinoma
}

\author{
MS PHILLIPS, V BARKER \\ From the Chest Unit, Papworth Hospital, Papworth Everard, Cambridge
}

Cytological examination of material obtained by percutaneous thin needle lymph node aspiration is an established diagnostic technique. ${ }^{1}$ The method for obtaining such material has been well described, ${ }^{2}$ but there are no recent reports of its use in patients with bronchial carcinoma who have enlarged peripheral lymph nodes at presentation. We report our results of the past seven years to show the value of the technique in the diagnosis and management of bronchial carcinoma.

\section{Method}

From September 1977 to April 1984 percutaneous needle aspiration of 44 enlarged lymph nodes ( 40 supraclavicular, four axillary) was performed in 42 patients with suspected bronchial carcinoma (in two patients bilateral supraclavicular glands were aspirated). After application of local anaesthetic to the skin, the nodes were punctured by a 21 gauge ("green") needle, through which node tissue was aspirated into a plastic syringe. This material was promptly smeared on to a microscope slide, fixed immediately in alcohol, and screened after routine Papanicolaou staining. If simple aspiration yielded no material, injection of $0.5-$ $1.0 \mathrm{ml}$ of saline into the node followed immediately by aspiration was usually successful.

\section{Results}

Malignant cells were found in $37(84 \%)$ aspirates, confirming the diagnosis of malignancy in $36(86 \%)$ patients. Thirty three patients had bronchial carcinomasmall cell in 13, squamous in 11, adenocarcinoma in six, and undifferentiated in three. Breast carcinoma was diagnosed in one patient and lymphoma was suspected in two.

In eight patients material was subsequently submitted for histological examination (one necropsy, five lymph node excision biopsies, and two bronchial mucosal biopsies). In all six cases of carcinoma the cytological diagnosis was confirmed with agreement for cell type. Histological examination of lymph nodes excised from the two patients thought from lymph node aspiration to have lymphoma, however, showed small cell carcinoma in one and poorly differentiated adenocarcinoma in the other.

In six other patients diagnosed from lymph node aspiration as having bronchial carcinoma, material from alternative sources-sputum (3), sputum and pleural fluid (1), bronchial brushings (1), and bronchial aspirate (1)showed carcinoma cells on cytological examination with cell type agreement in each case.

Address for reprint requests: Dr MS Phillips, Papworth Hospital, Papworth Everard, Cambridge CB3 8RE.

Accepted 22 October 1984
There were six patients in whom lymph node aspiration did not give a diagnosis. In one there were cells suggestive but not diagnostic of small cell carcinoma. This diagnosis was confirmed by excision lymph node biopsy. In the other five, lymphoma was diagnosed by excision lymph node biopsy in two and adenocarcinoma by pleural biopsy in another. In two no histological diagnosis was made (one patient died and one received radiotherapy for superior vena caval obstruction).

\section{Discussion}

Lymph node aspiration is painless, quick, and without complications. Requiring no special skills, it can be performed on outpatients to confirm the diagnosis of inoperable bronchial carcinoma within hours.

The diagnostic yield is high and compares favourably with that of other methods of confirming bronchial carcinoma by biopsy of intrathoracic lesions. ${ }^{3}$ Our experience suggests that this technique is accurate in the diagnosis of bronchial carcinoma but not lymphoma. Most reports conclude that lymph node aspiration is less reliable in lymphoma than carcinoma. ${ }^{45}$ If lymphoma is suspected clinically we do not recommend this approach.

Needle aspiration of enlarged lymph nodes in patients with suspected bronchial carcinoma will usually confirm the diagnosis. As with other techniques that rely on cytological rather than histological examination, however, a negative or equivocal report is without value. In this event the aspiration could be repeated, but if it again fails to provide the diagnosis the node should be removed surgically for histological examination.

We thank Drs JE Stark and PGI Stovin for allowing us to report these results and for their help in the preparation of this paper.

\section{References}

1 Frable WJ. Thin needle aspiration biopsy. Major problems in pathology. Vol. 14. Philadelphia: WB Saunders Company, 1983:74-118.

2 Knight RK. Bronchoscopy and other biopsy techniques. In: Emerson P, ed. Thoracic medicine. London: Butterworths, \& 1981:214.

3 Payne CR, Stovin PGI, Barker V, McVittie S, Stark JE. Diagnostic accuracy of cytology and biopsy in primary bronchial carcinoma. Thorax 1979;34:294-9.

4 Bloch M. Comparative study of lymph node cytology by puncture and histopathology. Acta Cytol 1967;11:139-44.

5 Loseke L, Craver LF. The diagnosis of Hodgkin's disease by aspiration biopsy. Blood 1946; 1:76-82. 